\section{A Sociedade de Medicina e Cirurgia do Rio de Janeiro: a gênese de uma rede institucional alternativa}

\author{
The Rio de Janeiro \\ Medical and Surgical \\ Society: the genesis of \\ an alternative \\ institutional network
}

\section{Luiz Otávio Ferreira \\ Marcos Chor Maio \\ Nara Azevedo}

Luiz Otávio Ferreira é professor adjunto da Universidade do Estado do Rio de Janeiro (UERJ), e, com Marcos Chor Maio e Nara Azevedo, integra o quadro de pesquisadores da Casa de Oswaldo Cruz/ Fundação Oswaldo Cruz (COC/Fiocruz).

Avenida Brasil, 4036, sala 401

21040-361 Rio de Janeiro - RJ Brasil

$$
\text { E-mail: }
$$

Fax: (021)590-3489
FERREIRA, L. O.; MAIO, M. C. e AZEVEDO, N.: 'A Sociedade de Medicina e Cirurgia do Rio de Janeiro: a gênese de uma rede institucional alternativa'. História, Ciências, Saúde-Manguinhos,

IV(3): 475-491, nov. 1997-fev. 1998.

Este artigo aborda a história da medicina no Brasil no final do século XIX, a partir da análise do surgimento da Sociedade de Medicina e Cirurgia do Rio de Janeiro. Nossa hipótese é de que, a partir da década de 1880, a reformulação das instituições e a diversificação da coletividade médica iniciaram a estruturação de um campo de relações sociais específicas aos praticantes da medicina. Diante da crise das instituições médicas oficiais, verifica-se o surgimento de grupos médicos alternativos que, à margem da tutela estatal, se articularam em torno de objetivos comuns, em especial, a construção de um conhecimento médico nacional, que tivesse relevância no cenário científico internacional da época.

PALAVRAS-CHAVE: história da medicina, instituições médicas, medicina brasileira.

FERREIRA, L. O., MAIO, M. C. e AZEVEDO, N.: 'The Rio de Janeiro Medical and Surgical Society: the genesis of an alternative institutional network'. História, Ciências, Sauide-Manguinbos,

IV(3): 475-491, nov. 1997-feb. 1998.

Creation of the Rio de Janeiro Medical and Surgical Society serves as the basis for this study of late-19th-century medicine in Brazil. The bypothesis is that beginning in the 1880 s changes to institutions and the diversification of the medical community inaugurated the structuring of a field of social relations specific to medical practitioners. With official medical institutions undergoing crises, alternative groups that emerged outside the government framework worked together toward common ends, particularly the construction of a kind of Brazilian medical knowledge that could play a role on the international scientific scenario.

KEYWORDS: history of medicine, medical institutions, Brazilian medicine. 
1 As sociedades científicas no século XIX na América Latina têm sıdo investigadas por inúmeros pesquisadores atraíclos pelo tema em face de sua relevância para $o$ estudo da

Institucıonalização da ciência na reguão. Em 1992, a revista Interciencia (mai-jun., vol. 17, $\mathrm{n}^{2}$ 3) dedicou um número especial ao assunto, oferecendo um panorama clas investıgações que vêm sendo realizadas. Um outro estudo importante é o cle Saldaña e Azuela (1994) sobre as socreclacles científicas e a profissionalização da ciência no México.

\section{Introdução}

A o longo de sua história, a ciência revestiu-se de variadas A figuras institucionais até chegar ao instituto de pesquisa que conhecemos na atualidade, que apareceu no final do século XIX. Entre os séculos XVI e XVIII, as formas habituais de agrupamento científico foram as academias e as sociedades, compostas pelos interessados em trabalhar em prol do movimento científico. Além de servir de veículo às preocupações utilitárias, como o desenvolvimento de técnicas de navegação, seu objetivo era estimular os individuos a realizar pesquisas, recompensá-los pelos êxitos obtidos e facilitar a comunicação das atividades científicas existentes, principalmente, após haver passado a publicar periódicos que divulgavam resultados e críticas (Hall, 1988). Porém, já ao final do século XVII, o papel das sociedades modifica-se: as características iniciais de diletantismo e amadorismo cedem lugar a uma organização de tipo profissional. Dedicadas menos à promoção da ciência do que ao seu desenvolvimento, as sociedades já não abrigam os homens de cultura geral e, progressivamente, tornamse restritas aos especialistas. Na América Latina, as sociedades científicas apresentam traços e uma evolução mais ou menos semelhante às congêneres européias que lhes servem de modelo. Para os historiadores da ciência latino-americana, ${ }^{1}$ embora muitas sociedades tivessem curto período de existência e funcionassem mais como órgão de prestígio acadêmico e social do que um fórum de polêmicas científicas, sua proliferação é prova da vitalidacle da ciência nesses países, mesmo que não seja passível de comparação com o associativismo dos países europeus e/ou norte-americano.

Segundo a linha de argumentação desses estudos, pode-se avaliar melhor o desempenho dessas sociedades se considerarmos as dificuldades do contexto social e cultural nos quais elas se desenvolveram. Os inúmeros casos analisados mostram que a criação das sociedades científicas obedeciam a motivações variadas: desde atender as necessidades das jovens nações independentes na América em busca de conhecimentos sobre seu território, passando pelas aspirações dos cientistas desses países, até se tornarem organizações de profissionais especializados já no final do século XTX. A tradição de estudos sobre a natureza, que provinha da época colonial, mantevese com o aparecimento dos Estados nacionais, sendo um dos objetivos centrais dessas sociedades o desenvolvimento de projetos que visavam o reconhecimento do território nacional, a classificação e o estudo e aproveitamento dos recursos naturais. Não por acaso, floresceram novas organizações como as relacionadas à geografia, à estatística e a outras especialidades que adquiriram importância na organização dos novos países, fundamentando uma política de defesa territorial, econômica e de povoação. 
Embora muitas sociedades tivessem caráter privado, os interesses de Estado, indubitavelmente, desempenharam papel-chave não apenas em sua manutenção, mas também no amparo a outras iniciativas como a fundação de bibliotecas, a organização de museus, a realização de expedições científicas, funcionando assim como agente da promoção de atividades cultas no Novo Mundo. Aos propósitos civilizatórios da ciência somava-se seu caráter utilitarista; a ciência deveria estar a serviço da modernização do país. Além de assessorar os governos em várias matérias, e propaganda do ideário cientificista, as sociedades se converteram num espaço de institucionalização da ciência, estimulando debates científicos e divulgando o conhecimento através de publicações. Muitas vezes funcionavam como um grupo de pressão não apenas em relação à 'comunidade' científica, mas também ao poder político local.

Assim como nos países europeus, verifica-se a tendência à modificação do papel dessas sociedades à medida que a ciência, ao final do século XIX, passou a se realizar nas universidades e institutos de pesquisa. A partir de então, as sociedades perdem seu caráter generalista e tornam-se cada vez mais a expressão associativa de profissionais organizados por disciplinas especializadas.

No Brasil, tem-se dispensado pouca atenção a esse tipo de organização da ciência. Tendeu-se a privilegiar as 'modernas' instituições de pesquisa (institutos) e de ensino (universidades) que apareceram ao longo do século XX (Schwartzman, 1979). Também os estudos desenvolvidos em torno da implantação de disciplinas científicas (Azevedo, 1956; Ferri e Motoyama, 1979-81) tratam marginalmente o papel institucionalizador das sociedades. A Sociedade de Medicina e Cirurgia do Rio de Janeiro (SMCRJ), criada em 1886, desperta interesse pela iniciativa pioneira de promover os primeiros congressos científicos ocorridos no país, instituindo assim uma nova forma de manifestação pública da 'comunidade' médica. Além disso, ao pretender organizar-se como uma instituição científica não dependente do Estado, colocava em discussão a questão da autonomia da ciência.

O caso da SMCRJ ilustra também uma característica marcante da história da ciência brasileira do século XIX: a atividade científica e o trabalho profissional foram práticas inseparáveis. O exercício profissional da medicina representou uma das poucas alternativas disponíveis para os indivíduos interessados em ciência, explicandose assim por que as sociedades científicas mais importantes foram organizadas por médicos.

Detemo-nos aqui apenas no período de sua criação, quando, para afirmar-se no cenário médico nacional, procurou distinguirse da antiga Academia Nacional de Medicina. 


\section{A origem da medicina oficial}

É costume entre os historiadores mais tradicionais localizar na criação e evolução das instituições de ensino o foco mais importante do processo de institucionalização da medicina no Brasil clurante o século XIX. Desse modo, tem se dado destaque à instalação das academias médico-cirúrgicas do Rio de Janeiro (1813) e da Bahia (1815) e, posteriormente, a transformação dessas instituições em faculdades de medicina (1832). Pouca atenção tem sido dada a certas características sociais e culturais da medicina brasileira clo período colonial, como, por exemplo, o predomínio dos cirurgiões dos mais diferentes níveis de formação ou a convivência de medicinas inscritas em três tradições culturais (indígena, africana e européia). Tudo se passa como se a tradição médica do período colonial tivesse sido extinta com a criação das instituiçôes de ensino médico.

$O$ mesmo pode ser dito quanto às sociedades de medicina criadas durante o século XIX. Tal abordagem perde de vista o papel desempenhado por estas instituiçôes científicas que foram, em diferentes conjunturas históricas, atores importantes no processo de institucionalização da medicina brasileira durante o século passado.

Criada em 1829, apenas alguns anos após a proclamação da Independência política do país, a primeira sociedacle méclica a Sociedade de Medicina do Rio de Janeiro (SMRJ) - concretizava o sentimento de liberdade vivido pelos médicos e cirurgiões brasileiros que não estavam mais submetidos a constrangimentos e restriçôes impostos pelo monopólio profissional exercido pelos colegas portugueses.

A idéia de fundar a SMRJ nasceu entre um pequeno grupo de médicos e cirurgiões que exerciam suas atividades no principal hospital do Rio de Janeiro, a Santa Casa da Misericórdia. Liderados pelo médico italiano Luiz Vicente De-Simoni e pelo cirurgião brasileiro Joaquim Cândido Soares de Meirelles, aderiram ao projeto dois médicos franceses, José Francisco Xavier Sigaud e João Maurício Faivre, e o jovem médico brasileiro José Martins da Cruz Jobim.

Entre os três fundadores estrangeiros da SMRJ, existia uma situação similar: ter imigrado devido a perseguições políticas sofridas em seus países de origem. Quanto aos dois brasileiros, clestaca-se o fato de pertencerem à primeira geração de médicos nacionais formados pela Faculdade de Medicina de Paris, um tipo de formação que se tornaria cada vez mais comum no decorrer do século XIX. De comum entre brasileiros e estrangeiros havia a experiência européia, sobretudo francesa, que os fazia compartilhar os mesmo ideais científicos.

A fundação desta sociedade médica está relacionada ao início da institucionalização da higiene no país (Machado et al., 1978; 
Luz 1982; Azeredo,1978). À diferença das efêmeras sociedades científicas criadas no Brasil no final do período colonial - a Academia Científica do Rio de Janeiro (1771-72) e a Sociedade Literária do Rio de Janeiro (1786-90) - a SMRJ tinha um projeto institucional e científico bastante definido. Era uma instituição moldada segundo as concepções políticas e teóricas do movimento higienista europeu do final do século XVIII, particularmente o francês (Lécuyer,1986; Goubert,1982). Isso implicava a adesão ao chamado neo-hipocratismo, uma concepção ambientalista da medicina baseada na hipótese da relação intrínseca entre doença, natureza e sociedade. Do ponto de vista político, a filiação ao higienismo significava a consciência da necessidade de converter a saúde numa questão de interesse público e de competência estatal (Rosen, 1994, Foucault, 1982).

Também podemos atribuir a criação da SMRJ à influência do movimento ilustrado que, desde o final do século XVIII, vinha mobilizando políticos e intelectuais luso-brasileiros em torno da idéia de reforma e modernização do antigo sistema colonial português. Uma das principais diretrizes do movimento ilustrado foi a dinamização da economia (agricultura e mineração) brasileira. Para alcançar tal objetivo foram patrocinados inúmeros empreendimentos científicos (publicação de memórias originais, tradução de textos científicos estrangeiros, viagens de estudo e pesquisa, expediçôes científicas, criação de museus de história natural, sociedades científicas e de instituições de ensino) com a intenção de conhecer e explorar os recursos naturais, sendo a afirmação do valor utilitário da ciência o legado cultural desse movimento (Dias, 1968; Nizza da Silva, 1988). A primeira sociedade de medicina criada no Brasil foi herdeira desse movimento cientificista, na medida em que tinha a intenção explícita de promover a institucionalização da medicina afirmando seu valor utilitário para a construção de uma sociedade civilizada nos trópicos (Kury, 1994). O conhecimento das complexas relações entre o clima (leia-se natureza tropical) e as doenças no Brasil era algo indispensável, principalmente no que se refere ao aclimatamento do homem europeu.

Do ponto de vista organizacional, a sociedade de medicina copiava o modelo francês. Seu corpo societário era composto de 25 membros titulares e de um número ilimitado de membros honorários e correspondentes. Para o ingresso como membro titular, exigia-se do candidato diploma de médico, cirurgião, boticário, botânico, químico ou naturalista, um trabalho escrito sobre ciências médicas ou naturais e a indicação por parte de um ou mais membros titulares. O fato da SMRJ aceitar em seus quadros botânicos, químicos e naturalistas assinala seu propósito de se constituir como uma sociedade científica de caráter mais amplo e 
2 Segunclo Sigaud, a SMRJ, sufocada pela indiferença dos de fora, deveu seu crescimento aos esforços de seu primeiro presidente (Meirelles) e seu primeiro secretário (De-Simoni). “...a ambiçĩo e o espírito de compadresco provocaram mais tarcle rivalidades, semearam o desalento e ameaçaram a sociedade... . Graças à pruclência e ao zelo cle alguns membros, um espírito de atividade veio a propósito reanimar sua existência; e é quando as vantagens desse espírito se faziam melhor sentir que a sociedacle pelo voto unânime cle seus membros clesapareceu como um homem forte e vigoroso atacado de uma apoplexia fulminante, para clar lugar à Academia Imperial de Medicina, instituição nova, oferenda de remuneração feita pelo governo à sociedade, ato de transformação orgânıca no sentido literal e científico" (Diärio de Saúde, $\mathrm{n}^{2} 25$, 1835, p. 217). não como uma associação exclusivamente voltada para a medicina. Além disso, a inclusão dos cirurgiões refletia o fato deles constituírem a parcela mais significativa dos praticantes da medicina no início de século XIX.

A fragilidade institucional foi o problema crônico enfrentado pela SMRJ. Mesmo sendo uma sociedade científica formalmente reconhecida pelo governo imperial, ela não contava com o sustento oficial para sua manutenção, dispondo exclusivamente dos recursos obtidos com as contribuições obrigatórias dos membros titulares. A situação agravou-se durante a crise política decorrente do afastamento de d. Pedro I, ocorrido em 1831. A sociedade de medicina só conseguiu sobreviver graças ao patrocínio estatal obtido a partir de 1835 , quando a SMRJ passou a ser denominada Academia Imperial de Medicina (AIM).

Essa não foi uma mera mudança de nomes, mas uma alteração significativa do projeto original, que acabou tendo o repúdio de José Francisco Xavier Sigaud, um dos fundadores da SMCRJ, sobretudo porque trazia como conseqüência a ingerência direta do governo nos assuntos da sociedade científica. ${ }^{2}$

Esta opção implicou uma reestruturação interna da instituição, modificando-se totalmente a composição de seus membros. Foram instituídas quatro novas categorias de sócios: honorários, titulares, adjuntos e correspondentes. Os sócios eram distribuídos em seções segundo suas respectivas especialidades com predomínio de uma sobre as outras: Seção Médica -15 honorários, 25 titulares e 11 adjuntos; Seção de Cirurgia - 11 honorários, 15 titulares e 9 adjuntos; Seção de Farmácia - 7 honorários, 11 titulares e 5 adjuntos. Cada seção poderia ter um número ilimitado de sócios correspondentes. A condição de membro titular ou adjunto, posição que dava direito a participação efetiva na vida institucional, era conquistada através dos mesmos critérios definidos no tempo da SMRJ. Os honorários eram escolhidos entre médicos e cientistas nacionais e estrangeiros de reconhecida competência por meio de eleição. Mas, independentemente do critério de seleção, todos os candidatos a sócios tinham que ter seus nomes obrigatoriamente aprovados pelo governo.

Além disso, o que marcou a diferença entre a SMRJ e a AIM foi o fato dessa última ter funcionado como órgão corporativo, garantindo privilégios para seus membros e criando mecanismos de definição de uma medicina oficial. $O$ artigo 7 do Estatuto da AIM (1835, p. 7) determinava que "o lugar de membro da Academia é um título de recomendação para todas as comissões ou empregos relativos ao exercício da medicina; e a ela não poderão ser admitidos aqueles médicos, cirurgiões e farmacêuticos que tenham afixado nos lugares públicos ou divulgado pela imprensa anúncios sobre curativos que fizerem ou sobre a distribuição e venda de remédios 
que não tenham previamente submetido ao exame e aprovação da AIM, ou de qualquer das faculdades de medicina do Império. As suas memórias serão rejeitadas sem discussão." Esta foi uma diferença importante, pois instituía um monopólio profissional baseado exclusivamente no pertencimento aos quadros de sócios. Isso significava a destinação a estes médicos de parte substantiva do reduzido mercado de trabalho da época, os cobiçados postos públicos. Muito mais do que subsídios financeiros, este privilégio selou a aliança entre os médicos da AIM e o Estado imperial, imprimindo à medicina um caráter oficial.

Todavia, os privilégios corporativos não tiveram, a longo prazo, um efeito positivo. Sua obtenção foi acompanhada pela gradual perda de autonomia institucional que restringiu muito o campo de influência da AIM. Os estatutos de 1835 determinavam um rígido controle da vida administrativa e científica por parte da burocracia estatal numa forma idêntica à que seria adotada mais tarde nas faculdades de medicina.

Assim, encerrava-se a fase de maior dinamismo institucional. No período que se estende de 1831 a 1843 , as sociedades de medicina não apenas mantiveram com regularidade a publicação de periódicos científicos, como também detiveram prestígio político suficiente para influir na construção do aparato institucional da medicina, destacando-se, nesse caso, a formulação do projeto de implantação das faculdades criadas em 1832 no Rio de Janeiro e na Bahia. Note-se que, por intermédio dos periódicos e de outras formas de aparição pública (discursos, relatórios, projetos, consultas), se estabelecia contato direto com os setores letrados da Corte e com a elite política governante, conferindo, assim, ao discurso médico uma audiência mais ampla. A extinção, em 1843, desse veículo de comunicação, substituído pelos anais oficiais de circulação restrita, enclausurou a AIM na rotina das reuniões formais cada vez menos freqüentadas (Ferreira, 1996).

A falta de autonomia institucional e o isolamento intelectual foram as causas da estagnação da AIM, o que não tardou a ser percebido pelos próprios acadêmicos. Por exemplo, em junho de 1867 (pp. 17-23), o editor dos Annaes Brasilienses de Medicina, órgão oficial da AIM, lamentava o estado de abandono da medicina no Rio de Janeiro, onde, segundo ele, imperava a indiferença e a passividade dos médicos diante dos progressos da medicina. Lastimava também que a iniciativa de criar uma outra sociedade médica, a Sociedade de Ciências Médicas do Rio de Janeiro, tivesse fracassado. No Rio de Janeiro, dizia o redator oficial da AIM, não era possível que durasse por muito tempo um jornal de medicina ou uma associação médica que não contasse com o auxílio dos poderes do Estado. A consciência do problema não ficou restrita aos acadêmicos, ela também foi assumida por outros 
3 Os periódicos independentes mais importantes que circularam nesse período foram Gazeta Médica do Rio de Janeiro, Gazeta Médica da Babia, O Progresso Médico, Revista Médica, União Médica e Brazil Médico. Uma análise do comportamento clestes periódicos foi feita por Edler (1992). médicos e, sobretudo, pelos estudantes de medicina, que expuseram suas opiniões críticas nos periódicos médicos independentes que circularam no Rio de Janeiro e na Bahia nas décadas de 1860 , 1870 e $1880 .^{3}$

A crise institucional fica ainda mais evidente ao se constatar sua pouca participação no movimento de renovação da medicina iniciado no Rio de Janeiro e na Bahia a partir da década de 1870. Este movimento, de cunho cientificista, contemporâneo ao advento das idéias positivistas e republicanas no Brasil, mobilizou médicos, intelectuais e políticos em torno de projetos que propiciaram o avanço do processo de institucionalização da medicina, inibido desde a década de 1850 por ocasião da primeira reforma do ensino médico que cerceou a liberdade acadêmica das faculdades. Sob a influência e/ou pressão política exercida pelo movimento de renovação da medicina, foram executadas as reformas do ensino médico em 1879 e 1884 (Edler, 1992); as reformulações da legislação sanitária em 1882 e 1884; a criação da Policlínica do Rio de Janeiro, em 1882, e do Instituto Pasteur do Rio de Janeiro, em 1888; a realização dos dois primeiros congressos médicos nacionais em 1888 e 1889 (uma iniciativa da SMCRJ); e o início da circulação regular do jornal Brazil Médico em 1887.

Nesse contexto, a reformulação do antigo estatuto, ocorrida em 1885, foi uma tentativa de sobrelevar o papel da instituição no movimento de renovação da medicina brasileira. Segundo o então presidente, o dr. Agostinho José de Souza Lima, a revitalização da instituição dependia, essencialmente, da superação de dois problemas crônicos: um de ordem financeira - o parco recurso oficial destinado à sua manutenção - e outro de natureza cultural - a reduzida participação da maioria dos sócios nas atividades da instituição (Annaes Brasilienses de Medicina, 1884, p. 125). Se os novos estatutos tinham propósitos modernizantes, isso não significava restabelecer a autonomia administrativa e científica da instituição perante o Estado, pois, simultaneamente à reformulação dos estatutos, o presidente Souza Lima reivindicava o aumento dos subsídios oficiais. Apesar disso, a eliminação do artigo 7 do estatuto de 1835, que garantia a exclusividade dos empregos públicos relacionados à saúde para os acadêmicos, enfraquecia os vínculos estreitos entre a AIM e o Estado imperial.

\section{Uma rede institucional alternativa}

O único trabalho existente sobre os primórdios da SMCRJ estabelece estreitos vínculos entre aquela instituição e as transformações políticas ocorridas naquele momento, mais especificamente a abolição da escravidão (1888) e a proclamação da República (1889). Este aspecto é destacado pela historia oficial da instituição: "Ainda 
que não se pretenda dar ao primeiro fato histórico a importância dos outros dois, jamais poderemos afastar a fundação da Sociedade de Medicina e Cirurgia do Rio de Janeiro das mesmas raízes históricas, ou seja, um movimento de libertação" (Queiroz, 1986, p. 14).

Assim, da mesma forma que a criação da SMRJ, em 1829, representou a 'libertação' da medicina brasileira do colonialismo português, o advento da SMCRJ significou a 'libertação' da medicina brasileira do elitismo da monarquia. Segundo esta versão, a SMCRJ surgiu como uma associação científica democrática, republicana e sensivel aos grandes problemas relativos à saúde pública, que contrastava fortemente com a AIM, cuja dependência do governo imperial cerceava a participação dos médicos tanto nos debates científicos, quanto nas formas de intervenção no mundo social. Esta interpretação baseia-se na comparação dos estatutos de ambas as sociedades, evidenciando-se o caráter restritivo e elitista da AIM e a flexibilidade da nova sociedade, sobretudo, no que diz respeito ao ingresso quase ilimitado a quaisquer candidatos médicos que desejassem integrar seu quadro social, contanto que fossem indicados por sócios da entidade.

Sem pretender refutar a validade de tais argumentos, merece atenção um aspecto que escapa à história oficial: a singularidade da SMCRJ deve-se menos à sua filiação republicana do que à sua inscrição numa rede de instituições médicas não oficiais empenhadas em lutar pela modernização científica e institucional da medicina brasileira. Integravam essa rede os periódicos Gazeta Médica da Babia (GMB) e Brazil Médico (BM). O primeiro surgiu em 1866 como um pólo de contestação à medicina oficial vinculando-se à chamada Escola Tropicalista Baiana, reconhecida como o limiar da pesquisa científica no campo da parasitologia. Sem endossar as idéias européias de determinismo racial, os membros deste agrupamento científico consideravam que as "doenças tropicais" conferiam um caráter 'nacional' à medicina, e deveria ser estimulado o seu desenvolvimento (Peard, 1990). Por sua vez, a revista Brazil Médico, fundada em janeiro de 1887 pelo médico Antônio Azevedo Sodré, também procurou estreitar os laços com a nova sociedade, tendo vários de seus colaboradores ingressado em seu quadro de sócios.

Ao registrar o recebimento do primeiro número da revista da SMCRJ, de agosto de 1886, a GMB não apenas parabenizou a nova associação, como também aproveitou para dirigir críticás à "medicina da Corte". Segundo a GMB (1886, p.92), a revista da sociedade "preenche um grande vácuo, que já se fazia sentir no movimento médico-profissional da capital do Império. Resistindo a todas as causas da indiferença e apatia, um grande número de colegas ilustrados e de reputação firmada no país, residentes na Corte, promoveram e realizaram a fundação de uma sociedade." 
1 A febre amarela foi, clescle 1850, o principal problema sanitário do Rio de Janeiro. Durante a clécada de 1880 , as epidemias da doença tornaram-se ainda mais graves, exigindo dos médicos brasileiros a formulação de planos para combatê-la. Sobre o assunto é

indispensável a consulta aos trabalhos de Chalhoub (1994) e de Benchimol (1996, 1995).
A contestação à tradição médica até então dominante não se restringia ao grupo vinculado à GMB; o periódico carioca Brazil Médico também alinhou-se a esta posição e estabeleceu estreitos laços com a nova SMCRJ, tendo seu proprietário, o médico Azevedo Sodré, se transformado em uma de suas principais lideranças. Já no primeiro editorial, o Brazil Médico (15.1.1887) apresenta suas principais críticas à medicina oficial, ressaltando o descompasso existente entre o aumento do número de médicos no Brasil e a ausência de uma produção intelectual expressiva. As razões mencionadas para a ocorrência de tal fato eram duas: o mimetismo, medido pela aceitação acrítica da produção científica estrangeira em detrimento da nacional; e o reduzido número de revistas especializadas, que limitava muito a publicação de trabalhos científicos.

$\mathrm{Na}$ opinião dos editores da revista, a ciência brasileira não poderia prescindir de conexões internacionais, devendo, no entanto, operar leituras singulares, voltando sua ótica para as especificidades do país. Assim, Brazil Médico acreditava que "divulgando os trabalhos nacionais removeria em certos limites a apatia e o indiferentismo que entorpecem e dominam o grupo médico brasileiro".

Gozando de relativa autonomia frente aos interesses estatais, estas instituições formaram uma opinião relativamente independente e crítica do oficialismo representado pela AIM. Julgava-se que a atitude corrente entre os médicos da época - de 'apatia e indiferença' - decorria da falta de autonomia institucional e científica.

\section{Em busca de uma identidade própria}

A nova sociedade foi marcada por um espírito liberalizante, traço evidenciado, sobretudo, em seus critérios de recrutamento: não era exigida a apresentação de um trabalho científico, como na AIM, bastando um convite ou a indicação de um membro para o ingresso dos candidatos a sócios.

Por outro lado, a consulta aos seus boletins revela uma sociedade atuante e participava nas questões sociais de seu tempo: em reuniões realizadas semanalmente debatia-se desde a apresentação de casos clínicos ao tema candente da época - as epidemias, que grassavam na cidade, em particular, a febre amarela. ${ }^{\prime}$

Esta configuração não implicou, contudo, um desempenho melhor do que o da antiga academia, sobretudo no que tange à superação da atitude tradicional caracterizada como de indiferença e apatia, medida, à época, entre outros critérios, pelo grau de participação da vida associativa. Do ponto de vista quantitativo, 
5 Dados extraídos do Boletım da AIM do ano de 1886 e das atas das sessôes da SMCRJ, no período de janeiro a outubro de 1887 , publicadas na revista Brazil Médico. verifica-se que a SMCRJ demonstrou relativa capacidade de atração, chegando a aglutinar, em 1889, cerca de duzentos associados. Porém, ao analisar-se o comparecimento dos sócios às atividades rotineiras da sociedade, nota-se que a freqüência era extremamente baixa. No ano de 1887 , por exemplo, a média de comparecimento dos sócios às sessões foi de apenas dez, média exatamente igual à verificada para as sessões da AIM ocorridas em 1886. ${ }^{5}$

Assim, não se pode explicar o desempenho destas sociedades científicas pelas características que thes são atribuíclas - o elitismo de uma e o liberalismo da outra -, mas sim à forma específica de valorização conferida ao pertencimento a este tipo de organização acadêmica. A filiação a uma das duas agremiações se apresentava como um passaporte seguro para o acesso a uma cobiçada posição social: a elite médica (Coradini, 1997). Dessa forma, o título de sócio conferia ao seu portador o status de integrante do estrato superior da hierarquia social da medicina. A participação efetiva e constante na vida acadêmica não era uma exigência incontornável para que este objetivo fosse alcançado.

Por outro lado, deve-se considerar o período como o da gestação de uma 'comunidade' científica que se percebe e atua como tal, quando ainda estavam em negociação os padrões organizacionais e os valores que deveriam orientar o comportamento dos individuos. Tal situação é ilustrada numa das polêmicas que identificamos nas atas das reuniões da SMCRJ, em que se discute a natureza de suas funções por meio de uma controvérsia acerca clas formas adequadas de comunicação.

As opiniões dividiram-se em dois grupos principais: o primeiro argumentava que a sociedade deveria compensar a baixa repercussão entre a categoria médica, buscando legitimidade entre o público mais amplo, publicando os trabalhos e as atas das reuniões na grande imprensa. O segundo grupo, embora não desprezasse o tema da legitimidade social, estava mais preocupado com a constituição de uma esfera propriamente acadêmica, privilegiando assim os pares em detrimento dos leigos. Por isso, opunham-se à difusão dos assuntos tratados na sociedade em veículos não especializados. Desse modo, contraargumentavam, desvirtuava-se o projeto original e reproduziase um comportamento idêntico ao da AIM (Brazil Médico, 14.3.1887, p. 68).

Não é nossa intenção detalhar a polêmica que se estendeu por um longo período, mas chamar a atenção para as diferentes concepções organizacionais e as estratégias de legitimação social que estavam na pauta de discussões. Não havia ainda um padrão de atividade científica plenamente institucionalizado, embora possamos identificar o desenvolvimento da pesquisa científica até mesmo nos moldes mais modernos da época, a microbiologia. 
Vale mencionar que venceu a opinião do segundo grupo, passando-se a publicar as atas das reuniões e os trabalhos em Brazil Médico. Isso não apenas contribuiu para a consolidação do perfil científico desse periódico (que sobreviveu até a década de 1960), como também estreitaram-se os vínculos entre essas duas jovens instituições.

Em meio a esses debates e relacionada a tais preocupações, encontra-se uma inovação: a realização de congressos científicos até então inéditos no país. Assim, dava-se mais um passo em direção à institucionalização.

\section{O primeiro congresso médico brasileiro}

Antiga aspiração de representantes da categoria médica, o $1^{\circ}$ Congresso Brasileiro de Medicina e Cirurgia do Rio de Janeiro, realizado na cidade do Rio de Janeiro em setembro de 1888 , foi uma iniciativa pioneira de membros da SMCRJ, que, em 1887, incluíram um aditivo aos estatutos prevendo a sua realização anual (Brazil Médico, 22.9.1887, p. 82).

Azevedo Sodré defendeu a proposta, registrada em ata de uma das sessões da sociedade:

Faz menção à norma de proceder de outras sociedades estrangeiras;
faz sentir a indiferença e o esquecimento em que se vê mergulhada a
nossa pátria; lembra o papel pouco lisonjeiro que esta tem representado
nos grandes certames internacionais; salienta o grande número de
elementos esparsos, peculiares, ao nosso meio vasto e complexo, e faz
ver o proveito incontestável que adviria para a ciência, descle que eles
pudessem, congregados, ser perfeitamente aproveitados; faz sentir as
vantagens do congraçamento e da reunião da classe médica e,
finalmente, apela para a Sociedade de Medicina e Cirurgia, convidando-
a para que tome a sério a iniciativa da instalação anual de um Congresso
Médico Brasileiro (Brazil Médico, 10.11.1887, p. 147).

Embora não se identifiquem as referências acadêmicas de Sodré nessa passagem, pode-se perceber relações entre a proposição e a polêmica atraso/moderno que atravessou o campo intelectual e marcou o processo de modernização do país. Tratava-se, para a opinião ilustrada, de colocar o Brasil de acordo com os últimos padrões de civilização ditados pela sociedade européia.

Por meio dos congressos médicos, a SMCRJ buscou projetar-se no cenário científico e cultural do país, posição conquistada pela continuidade dos eventos ao longo do tempo e pela estratégia de realizá-los em diferentes estados do país. Assim, criou-se a possibilidade de estabelecer um tipo de relação inexistente entre grupos do Sul e do Norte, que sequer se conheciam, dadas não 
apenas as dificuldades provenientes das dimensões continentais do país, mas, sobretudo, pela configuração eminentemente local das instituições médicas até então. A participação estava aberta aos médicos nacionais e estrangeiros sob a condição do pagamento de uma taxa de inscrição e filiação à sociedade. $O$ número de participantes (141) foi expressivo, se considerarmos o universo intelectual da época, interessado e habilitado a escrever trabalhos e discuti-los publicamente (Anais do $1^{\circ}$ Congresso Brasileiro de Medicina e Cirurgia do Rio de Janeiro, 1889).

Do congresso, chama a atenção o nome escolhido para a prestigiosa função de orador, incumbido de pronunciar o discurso oficial na cerimônia de abertura: o médico carioca Júlio de Moura. Tal escolha não parece casual: Moura foi um dos clínicos de maior clientela na cidade do Rio de Janeiro, a par da intensa atividade no campo da experimentação, apresentando significativa produção de artigos, para os padrôes da época, e que o projetaram nacional e internacionalmente, em temas que o vinculavam diretamente a parasitologistas baianos: o beribéri e a hipoemia intertropical (Blake, 1899, vol. 5, pp. 266-8). Este perfil fazia de Moura o porta-voz ideal do movimento reformista. Não por acaso, seu discurso na solenidade de abertura do congresso tratou da questão da ética profissional entre os médicos, e da necessidade de se "reconstruir os alicerces da nosologia brasileira", lançados pelo pioneiro trabalho de Xavier Sigaud, Du climat et des maladies du Brésil (1844), referência obrigatória do campo que passaria a ser denominado de doenças nacionais. Segundo Moura, este era um dos mais adequados, senão o melhor campo de investigação para que os brasileiros ganhassem credibilidade no cenário científico internacional. Até então, conforme Júlio de Moura, o estudo das moléstias tropicais constituía tema privilegiado dos médicos europeus, "ingleses das Índias e dos cirurgiões da marinha francesa nas colônias". A produção dos brasileiros neste campo não passava de "um acanhado esforço", cujos resultados práticos ficavam restritos a um limitado círculo, e, para seu infortúnio, "não perpetuam nos anais da medicina o nome de muitos clínicos de nota".

A ciência médica brasileira viveria, segundo Moura, sob o efeito do colonialismo cultural, resumindo-se à "reprodução exótica daquilo que a civilização nos exporta". Por isso, convocou os participantes do congresso a protestar contra a "tutela científica" em que tinham viviclo até então. Moura também advertia a audiência para o perigo da retórica científica: sem a constituição de uma base autônoma e própria de conhecimento, o Brasil não acumularia um patrimônio científico sólido e relevante. Somente assuntos originais garantiriam algum lucro científico, o qual, no caso brasileiro, residia na investigação das "doenças tropicais" (Anais do $1^{\text {N }}$ Congresso Brasileiro de Medicina e Cirurgia, 1889, pp. 6-7) 
O programa de pesquisa sugerido por Moura veio a ser cumprido pela geração seguinte, que conseguiu libertar a ciência de laboratório (a microbiologia pasteuriana) da medicina de beira de leito, profissionalizando a atividade de pesquisa num espaço próprio: as instituições de pesquisa sustentadas pelo Estado. A partir da década de 1890, esta geração de médicos-cientistas, sediados nas cidades do Rio de Janeiro e de São Paulo, empreenderam esforços no sentido de produzir conhecimentos sobre as "doenças tropicais", assim como se envolveram diretamente em seu combate através da formulação e implementação de políticas públicas na área cla saúde.

\section{Conclusão}

Terá sido a SMCRJ um empreendimento bem-sucedido? De que maneira é possivel aferir seu êxito?

A resposta não deve ser buscada numa avaliação de seu desempenho baseada na participação efetiva dos associados nas atividades cotidianas da instituição. Nesse aspecto, a SMCRJ assemelhava-se à sua rival, a AIM. Em ambas, o número de sócios militantes sempre foi muito pequeno. Este fenômeno, comum às duas entidades, não é, portanto, indicador suficiente para aquilatarmos sua representatividade. O que pesa a favor da SMCRJ é a série de congressos médicos organizados a partir de 1888 e que ocorreram regularmente até as duas primeiras décadas do século XX. Uma vez institucionalizados, os congressos tornaram-se um evento de grande importância científica, tendo se transformado no fórum mais importante de discussão dos principais temas da ciência médica e da saúde pública no Brasil.

Desse ponto de vista, podemos considerar que o caso da SMCRJ se assemelha ao da primeira sociedade médica brasileira, a SMRJ. Ambas, em momentos distintos, procuraram estabelecer o papel próprio de uma sociedade científica no contexto cultural do século XIX. Enquanto a SMCRJ buscou legitimar-se instituindo o congresso científico como nova fórmula de expressão acadêmica e de inscrição na vida pública, a SMRJ, por sua vez, inaugurou o periodismo médico, privilegiando-o como meio através do qual o conhecimento médico era validado entre os pares e didaticamente divulgado à sociedacle (Ferreira, 1996). O valor estratégico do congresso científico promovido pela SMCRJ fica mais evidente quando sabemos que, no final século XIX, o periódico médico torna-se cada vez mais especializado, dificultando o acesso ao leigo. Desse modo, os congressos renovaram a capacidade da medicina de se posicionar na vida pública por intermédio de atividades de valor acadêmico.

No entanto, o sucesso relativo da SMCRJ, no que tange a sua organização acadêmica e visibilidade social, não foi suficiente 
para resolver o problema da dependência institucional em relação ao Estado. Na verdade, mesmo não sendo a SMCRJ um organismo estatal, o poder público pode não ser descartado como patrocinador indireto das atividades daquela sociedade científica.

\section{FONTES IMPRESSAS}

Anais do $1^{2}$ Congresso Brasileiro de Medicina e Cirurgia do Rio de Janeiro.

Rio de Janeiro, Imprensa Nacional, 1889

Annaes Brasilienses de Medicina. Jornal da Academia Imperial de Medicina.

Rio de Janeiro, tomo XIX, 1867; tomo XXXVI, 1884

Boletim da Academia Imperial de Medicina.

Rio de Janeiro, 1886

Brazil Médico,15.1.1887;14.3.1887; 22.9.1887; 10.11.1887.

Diário de Saúde, $\mathrm{n}^{2} 25,1835$

Estatutos da Academia Imperial de Medicina do Rio de Janeiro.

Rio de Janeiro, Tipografia Fluminense de Brito \& Cia, 1835

Gazeta Médica da Babia,

set. 1886.

\section{REFERÊNCIAS BIBLIOGRÁFICAS}

Ackerknecht, Erwin 1948

Azeredo, Paulo Roberto 1978

Azevedo, F. (org.) 1956

Benchimol, Jaime Larry 1996

Benchimol, Jaime Larry 1995

Benitez, Leonel Rodriguez 1992

Blake, Sacramento 1899

Cabreira, Leoncio Lopez-Ocon 1992

Capel, Horácio 1992
'Anticontagionism between 1821 and 1848'.

Bulletin of History of Medicine, 22, pp. 562-93.

'Classe social e saúde na cidade do Rio de Janeiro: primeira metade do século XX'. Revista do Museu Paulista, 25, pp. 129-66.

As ciências no Brasil.

São Paulo, Eclições Melhoramento, 2 vols.

Do Pasteur do micróbio ao Pasteur dos mosquitos: a febre amarela no Rio de Janeiro (1880-1903).

Tese de doutoramento, Universidade Federal Fluminense, Instituto de Ciências Humanas e Filosofia.

'Domingos José Freire e os primórdios da bacteriologia no Brasil'.

História, Ciências, Saúde - Manguinbos, vol. II(1), pp. 67-98.

'La geografia en el projecto nacional de Mexico independiente, 1824-1835.

La fundación del Instituto Nacional de Geografia e Estadisticas'. Interciencia, vol. 17, $\mathrm{n}^{2} 3$, pp. 155-60.

Dicionário Biblịgráfico Brasileiro. Rio de Janeiro, Imprensa Nacional.

'Medio siglo de atividades de la Sociedad Geografica de Lima'. Interciencia, vol. 17, $\mathrm{n}^{\mathrm{o}} 3$, pp. 147-54.

'El asociacionismo cientifico em IberoAmerica. La necesid de un enfoque globalizador'.

Interciencia, vol. 17, $\mathrm{n}^{2} 3$, pp. 168-76. 
Chalhoub, Sidney 1995

Chalhoub, Sidney 1994

Coelho, Edmundo 1995

Coradini, Odaci Luiz 1997

Dias, Maria Odila da Silva 1968

Edler, Flávio Coelho 1992

Ferreira, Luiz Otávio 1996

Ferri, Mario Guimarães e Motoyama, Shozo 1979-81

Figueirôa, Sílvia F. M. de 1992

Foucault, Michel 1982

Freites, Yajaira

1992

Goubert, Jean-Pierre (org.) 1982

Hall, A. Rupert 1988

Jordonova, L. J. 1981

Kury, Lorelai Brilhante 1994

Lécuyer, Bernad P. 1986

Lutz, Adolpho 1888

Luz, Madel T. 1982

Machado, Roberto et al. 1978
'Febre amarela e ideologia racial no Rio de Janeiro do século XIX'. Estudos Afro-Asiáticos, 27: 87-110.

Cidade febril: cortiços e epidemias na Corte Imperial.

Tese de livre-docência, Universidade de Campinas, Departamento de História.

'Físicos, sectários e charlatães: a medicina em perspectiva histórico-comparada'. Em Maria Helena Machado (org.), Profissöes de saúde: uma abordagem sociológica.

Rio de Janeiro, Editora Fiocruz.

'Grandes famílias e elite profissional na medicina no Brasil'.

História, Ciências, Saúde-Manguinbos, vol. II (3): 425-66.

'Aspectos da ilustração brasileira'.

Revista do Instituto Histórico e Geográfico Brasileiro, 278: 105-69.

As reformas do ensino médico e a profissionalização da medicina na Corte do Rio de Janeiro, 1854-84. Dissertação de mestrado, Universidade de São Paulo, Faculdade de Filosofia, Ciências e Letras.

O nascimento de uma instituição científica: os periódicos médicos brasileiros da primeira metade do século XIX. Tese de doutoramento, Universidade de São Paulo, Faculdade de Filosofia, Ciências e Letras.

História das ciências no Brasil, São Paulo, EPU, 3 vols.

'Associativismo científico no Brasil: o Instituto Histórico e Geográfico Brasileiro como espaço institucional para as ciências naturais durante o século XIX'. Interciencia, vol. 17, $\mathrm{n}^{2} 3$, pp. 141-6.

A microfisica do poder. Rio de Janeiro, Graal.

'La Academia de Ciencias Fisicas, Matemáticas y Naturales de Venezuela (1917-79): una realidad aparte de la ciencia?'. Interciencia, vol. 17, n 3, pp. 61-7.

La médicalisation de la Société Française, 1770-1830. Waterloo/Ontario, Historical Reflection Press.

A revolução na ciência, $1500-1750$.

Lisboa, Edições 70.

'Earth science and environmental medicine: the synthesis of the late enlightenment'. Em Images of the earth essays in the bisory of the environmental science. Londres, The British Society fot History of Science.

'Entre nature et civilisation: les médecins brésiliens et l'identité nationale (1830-50)'. Cabiers du Centre de Recherches Historiques, 12, pp. 159-72.

'L'hygiene en France avant Pasteur: 1750-1850'. Em Claire Salomont-Bayet, Pasteur et la révolucion pastorienne. Paris, Payot.

A opilação ou bipoemia intertropical e sua origem ou Ankylostoma duodenal e Ankylostomíase. Rio de Janeiro, Typ. e Lith. de Machado \& C.

Medicina e ordem politica. Politicas e instituições de saúde (1850-30). Rio de Janeiro, Graal.

Danação da norma: medicina social e constituição da psiquiatria no Brasil. Rio de Janeiro, Graal. 
Nizza da Silva,

Marıa Beatriz

1988

Obregon, Diana 1992

Peard, Julyan G. 1990

Queiroz, Julio Sanderson 1986

Rosen, George 1994

Saldaña, Juan Jose e

Azuela, Luz Fernanda 1994

Santos Filho, Lycurgo 1991

Santos Filho, Lycurgo 1977

Schwartzman, Simon 1979
'O pensamento científico no Brasil na segunda metade do século XVIII'. Ciência E Cultura, 40 (9): 859-68.

'La Sociedad de Naturalistas Neogranadinos o la invención de una tradición'. Interciencia, vol. $17, \mathrm{n}^{\circ} 3$, pp. 135-40.

The Tropicalista School of Medicine of Babia, Brazil, 1860-1889.

Tese de doutoramento, Columbia University.

Memória da Sociedade de Medicina e Cirurgia do

Rio de Janeiro em um século de vida. Rio Janeiro, RioArte/MEC.

Uma bistôria da saúde pública.

São Paulo, Hucitec/Unesp/Abrasco.

'De amateurs a profisionales. Las sociedades científicas mexicanas en siglo XIX'. Quipu, vol. 11, $n^{2} 2$, pp.135-72.

História geral da medicina brasileira. São Paulo, Hucitec/Edusp, vol. 2.

História geral da medicina brasileira. São Paulo, Hucitec/Edusp, vol. 1.

Formação da comunidade científica no Brasil. São Paulo, Companhia Editora Nacional/Finep.

Recebido para publicação em outubro de 1997. 